\title{
Condicionantes Políticas y Estratégicas de la Demanda Marítima Boliviana
}

Politic and Strategic Constraints of the Bolivian Demand for a Sovereign Access to the

Pacific

Cristián Faundes*

\section{Resumen}

En el texto se presentan las condicionantes políticas y estratégicas que enmarcan la demanda marítima boliviana por una salida útil, libre y soberana al Pacífico, en el que se observa que el escenario político y estratégico actual que determina a los países involucrados restringe las posibilidades de establecer una negociación que pueda resolver el conflicto en términos satisfactorios.

Palabras clave: Demanda marítima boliviana; reivindicación; relaciones Bolivia Chile.

\begin{abstract}
This article presents the political and strategic constraints that frame the Bolivian demand for a useful, free and sovereign access to the Pacific. The author observes that the actual political and strategic scenario that determines the actions of the countries involved limits the possibilities to initiate a negotiating process to solve the conflict.
\end{abstract}

Keywords: Bolivian maritime demand; Bolivian vindication; Bolivia-Chile foreign affairs.

\section{Introducción}

La demanda marítima boliviana por una salida útil, libre y soberana al Pacífico se desarrolla en un marco de acción que actualmente imposibilita un arreglo según los términos planteados por Bolivia. Una serie de condicionantes políticas y estratégicas entorpece las posibilidades de diálogo, pero sobretodo encuadra de manera determinante las opciones, al punto que se hace prácticamente imposible vislumbrar fórmulas de arreglo según las condiciones que lo perfilan en el momento actual. En el presente ensayo se postula que la demanda marítima boliviana por una salida útil, libre y soberana al océano Pacífico no cuenta actualmente con las condiciones necesarias para

\footnotetext{
* Investigador del Centro de Estudios Estratégicos, Academia de Guerra del Ejército de Chile. Magíster en Seguridad y Defensa, mención Política de Defensa, por la Academia Nacional de Estudios Políticos y Estratégicos (Chile). Magíster en Ciencias Militares, mención Conflicto y Negociación Internacional, por la Academia de Guerra del Ejército (Chile). Graduado del Curso Avanzado de Seguridad y Defensa Hemisférica por el Colegio Interamericano de Defensa (OEA, Washington, DC). Ha participado en cursos de especialización en William Perry Center for Hemispheric Defense Studies y Eisenhower School for National Security and Resource Strategy (NDU, Washington, DC).

Conjuntura Global, Vol.3, n. 4, out./dez., 2014, p. 218-225. 
estructurar una negociación viable. De acuerdo con lo anterior, es requisito alterar estas condicionantes políticas y estratégicas para aspirar a desarrollar una negociación que permita resolver el conflicto. La revisión de este tema cobra vigencia por la demanda de Bolivia ante la Corte Internacional de Justicia en La Haya, en que el país altiplánico postula que Chile tiene la obligación de negociar para conceder a Bolivia un acceso totalmente soberano al océano Pacífico.

Los conflictos en general "tienen su origen en una diferencia de intereses o de deseos, en aspiraciones incompatibles que inducen a las partes a enfrentarse en el intento de lograr su objetivo" (Martínez, 1999: 17). En este punto cabe precisar que el caso en estudio obedece a un conflicto propiamente tal, donde específicamente una de las partes está dispuesta a causar daño al otro por conseguir sus objetivos. La demanda marítima boliviana por una salida útil, libre y soberana al Pacífico constituye un objetivo nacional permanente, por lo tanto es transversal a toda la sociedad (o nación ${ }^{1}$ ) y atemporal (CEEAG, 2014). Además se trata de un objetivo de carácter vital desde el momento en que los bolivianos asocian la cualidad marítima con su identidad, y que por lo tanto pretenden recuperar en miras a completar el proceso de construcción de Estado-Nación. En este tenor, la demanda boliviana choca con la voluntad chilena de mantener su soberanía e integridad territorial, estrechar lazos, generar confianzas, y finalmente negociar fórmulas para perfeccionar el acceso del país mediterráneo al Pacífico, aunque sin soberanía boliviana.

\section{Las condicionantes de Bolivia}

La principal condicionante que caracteriza actualmente a Bolivia es de carácter político, básicamente consiste en la restricción de opciones que limitan el rango de acción del poder gobernante. La Constitución de Bolivia del año 2009 establece que "El Estado boliviano declara su derecho irrenunciable e imprescriptible sobre el territorio que le dé acceso al océano Pacífico y su espacio marítimo" (Estado Plurinacional de Bolivia, 2009: art. 267). Para el gobierno en Bolivia, la salida soberana al mar hacia el Pacífico es una cuestión de reivindicación, en función de una supuesta deuda histórica de Chile. En vez de honrar un acuerdo de cesión de territorios alcanzado en 1904 con

\footnotetext{
${ }^{1}$ Corresponde precisar que a partir de la Constitución de 2009 Bolivia se ha definido como un Estado Plurinacional en razón de la existencia de 36 etnias en el país.

Conjuntura Global, Vol.3, n. 4, out./dez., 2014, p. 218-225. 
Chile, Bolivia plantea actualmente que Chile habría usurpado los territorios costeros dejando en situación de enclaustramiento a Bolivia, limitando sus posibilidades de desarrollo. Por tanto, esta "deuda" de carácter histórico para Bolivia no se limita a la pérdida de una "cualidad marítima", sino que a las riquezas que Chile ha podido explotar en los territorios otrora bolivianos. En el vecino país han llegado a cuantificar la explotación del guano, salitre y cobre a lo largo de todos estos años estableciendo cifras siderales... incluso, las conversaciones sobre los derechos de agua por el río Silala se entrampan en 2010 cuando en Bolivia deciden realizar un cobro histórico, de carácter retroactivo por las aguas que utiliza Chile en una zona que fue boliviana en el siglo XIX².

Por otro lado, la reivindicación como concepto es parte del proceso de refundación del Estado que encabeza Evo Morales. Su centralidad queda plasmada en particular en el Plan de Desarrollo Nacional de 2007, "El nuevo Estado participativo inclusivo se asentará en el poder democrático que emergió del proceso reivindicatorio de los pueblos originarios y los movimientos sociales, que posibilitó la presencia política de sectores tradicionalmente excluidos del Estado" (Estado Plurinacional de Bolivia, 2007: 110). La reivindicación marítima entonces tiene un asidero histórico y político, se vincula directamente con quienes han sido tradicionalmente relegados y han tenido la fuerza de alcanzar el poder político, junto a la llegada de Evo Morales a la presidencia, luego de años de postergación. Como podemos ver, el tema de fondo no es la soberanía marítima, sino que la reivindicación.

En definitiva, luego de años de mensajes de carácter reivindicacionista, especialmente en las celebraciones del "Día del Mar", cada 23 de marzo, un gobierno paceño no podría ofrecer a la opinión pública boliviana una salida soberana al mar que resulte de una negociación en que se entregue una compensación boliviana a cambio de una salida soberana al mar.

Respecto de la salida útil, libre y soberana al mar, cualquier puerto será insuficiente simplemente porque Bolivia no pide únicamente la restitución de la denominada "cualidad marítima" sino que en el fondo se encuentra la reivindicación de lo perdido en la Guerra del Pacífico. En la práctica, debemos constatar que Bolivia

\footnotetext{
${ }^{2}$ El tema sobre las aguas del Silala se trata en el marco de la Agenda de los 13 Puntos entre Chile y Bolivia (2006-2011). Se llega a un preacuerdo en 2009, pero en 2010 Bolivia busca insertar un acápite relativo al uso pasado de las aguas.

Conjuntura Global, Vol.3, n. 4, out./dez., 2014, p. 218-225. 
durante años tiene un acceso soberano al océano Atlántico, por Puerto Aguirre, que surge de una iniciativa totalmente privada, por medio de la cual el país cuenta con una salida soberana al mar a través de la Hidrovía Paraguay-Paraná ${ }^{3}$. A lo anterior, se suma Puerto Suárez, una zona franca en el puerto de Rosario cedida por Argentina, que Bolivia mantiene en desuso desde 1988. Como vemos, el requerimiento no es la "salida" propiamente tal, sino que la recuperación de lo perdido, según lo afirma el mismo Presidente Evo Morales en un discurso ante la Asamblea Legislativa el 22 de enero de 2011: “Atacama antes era de Bolivia. Es verdad. Esperamos recuperarla pronto" (Vergara y Toro, 2011).

A continuación es pertinente señalar la interacción entre una condicionante de carácter estratégico y otra de carácter político. La primera se refiere a la posición de menor poder relativo frente a Chile. Esta situación no sería tan importante en un diálogo bilateral normal, sin embargo es relevante en atención al objetivo paceño, que consiste en alterar las fronteras ya establecidas en el Tratado de 1904; un acuerdo de cesión de territorios que a su vez constituye una condicionante de carácter política. La existencia de este documento, su vigencia, validez y legitimidad (al ser ratificado por el mismo Congreso boliviano en la época), implican que Bolivia tiene que modificar el statu quo en las relaciones bilaterales, lo que es más difícil desde una posición inferior en términos de poder. Todo lo anterior radica en la necesidad de articular un mensaje convincente para llevar a Chile a la mesa de negociaciones, cosa que no ha conseguido en poco más de 100 años ${ }^{4}$. En razón de lo anterior es que cíclicamente la política exterior paceña busca apoyos de personalidades, países u organismos internacionales intentando forzar a Chile a negociar.

\section{Condicionantes de Chile}

Los acercamientos con Bolivia se desarrollan con el interés de mantener buenas relaciones vecinales y solucionar los problemas bilaterales, que abarcan diversidad de temáticas propias del quehacer político, económico, social de dos naciones limítrofes. Puntualmente en cuanto a la salida al mar, el esfuerzo de los últimos años de la

\footnotetext{
${ }^{3}$ Ver, http://www.puertoaguirre.com/

${ }^{4}$ El primer documento en torno a la revisión del Tratado de 1904, es el Memorándum de 1910 que emite la Cancillería boliviana el 22 de abril a Chile y Perú.

Conjuntura Global, Vol.3, n. 4, out./dez., 2014, p. 218-225. 
diplomacia chilena se centra en buscar opciones de perfeccionamiento de los instrumentos bilaterales existentes y los términos de operación en puertos, aduanas y el mismo tren Arica-La Paz, buscando perfeccionar las fórmulas para facilitar el acceso de Bolivia al Pacífico.

En cuanto a las condicionantes de Chile ante una eventual negociación para otorgar una salida soberana al mar para Bolivia, destacan las siguientes: 1.- La principal condicionante estratégica es que Chile no puede ceder una franja soberana a otro país dividiendo su territorio, menos voluntariamente, por lo tanto cualquier opción a una cesión territorial tendría que darse en el extremo norte de Chile en la forma de un corredor. 2.- Conforme lo anterior se revela la siguiente condicionante de carácter político-estratégico de alcance diplomático: cualquier opción por los territorios de Arica al extremo norte de Chile pasa por la decisión de Perú, en conformidad con el Tratado de 1929, que fija la frontera definitiva de ambos países; específicamente su Protocolo Complementario estipula que "Los Gobiernos de Chile y del Perú, no podrán, sin previo acuerdo entre ellos, ceder a una tercera potencia la totalidad o parte de los territorios que, en conformidad al Tratado de esta misma fecha, quedan bajo sus respectivas soberanías..."5. En consecuencia, esta alternativa implica incorporar también las condicionantes de Perú, que se examinan en el próximo apartado. 3.- La posibilidad de establecer un enclave con soberanía boliviana en la costa del Pacífico existe, pero conlleva una serie de complejidades que lo convierten en un asunto políticamente costoso para cualquier gobierno en ejercicio, pero en especial para el Estado y la Nación chilena, por lo tanto sería muy difícil que algún estadista lo quisiera asumir. Un acuerdo en tal sentido instalaría un quiste foráneo que alteraría el escenario estratégico en el norte de Chile con insospechados costos geopolíticos a futuro, que tendrían incidencia en las relaciones bilaterales con Bolivia. 4.- Otra condicionante política es el Tratado de 1904, por medio del cual Bolivia cede el territorio del litoral a cambio de una serie de compensaciones de Chile, que facilitan el acceso al mar al país altiplánico todavía al día de hoy. Bolivia goza de autonomía aduanera, preferencias tarifarias y facilidades de almacenamiento, exenciones tributarias y libre desplazamiento por las rutas de conexión con los puertos chilenos. En conjunto, los beneficios y privilegios de libre

\footnotetext{
5 _Tratado de paz entre Chile y Perú. 28 de julio, 1929. Disponible el 29 de diciembre, 2014 en: http://www.memoriachilena.cl/602/w3-article-71928.html

Conjuntura Global, Vol.3, n. 4, out./dez., 2014, p. 218-225. 
tránsito de que dispone Bolivia le cuestan a Chile cerca de US\$100 millones anuales (Ministerio de Relaciones Exteriores de Chile, 2014). En razón de lo anterior es que Chile no asume la existencia de deuda alguna, sobretodo porque el instrumento que fija los límites entre ambos países fue libremente firmado por las partes luego de años de negociación y ratificado por los respectivos congresos de acuerdo a las normativas vigentes. 5.- Esta última tiene sus raíces en otra condicionante política más profunda, la defensa de los intereses nacionales permanentes esenciales de cualquier Estado-Nación, tales como conservar la independencia y soberanía del país, y mantener la integridad del territorio nacional. 6.- Al respecto, tengamos en cuenta que desde una perspectiva política, la ciudadanía chilena tendría que pronunciarse respecto de la factibilidad de modificar las fronteras, lo que exige la celebración de un referéndum antes de la adopción de cualquier otra medida.

\section{Condicionantes de Perú}

Por su parte Perú, derrotado por Chile y abandonado por su aliado en la Guerra del Pacífico, pasa casi 50 años preocupado por el destino de Tacna y Arica ante el pavor de ver la posibilidad que alguno de esos territorios defendidos con sangre peruana terminara en manos de quien lo hubo abandonado en la Batalla del Alto de la Alianza, dejándolo a su suerte para luchar otros tres años invadido en su suelo ${ }^{6}$. Esta experiencia marca hasta el día de hoy las relaciones entre los tres vecinos, al punto en que es muy poco probable que algún mandatario limeño tenga el respaldo político, siquiera el interés de aprobar la cesión de una franja a Bolivia, aunque fuera por territorio que actualmente es chileno. De hecho, en el arreglo que alcanzan Chile y Perú para establecer la frontera definitiva en 1929, Perú prefiere entregar la preciada Arica al adversario que lo derrotó en el campo de batalla (Chile) antes que abrir la posibilidad a que la recibiera el aliado que lo abandonó en la guerra (Bolivia), conforme lo atestigua el protocolo complementario que ya revisamos.

\footnotetext{
${ }^{6}$ Las hostilidades de la Guerra del Pacífico terminan en 1883, sin embargo la fijación definitiva de límites entre Chile y Perú no ocurre sino hasta 1929.

Conjuntura Global, Vol.3, n. 4, out./dez., 2014, p. 218-225. 


\section{Reflexiones finales}

Con todo, la posibilidad de cualquier negociación con Bolivia pasa primero por desarrollar las condiciones políticas necesarias que permitan llegar a una instancia de diálogo fructífero, que permitan avizorar algún arreglo, que promuevan la resolución de esta situación de conflicto. Actualmente es clave el concepto de reivindicación, y el peso político que ha adquirido en la administración de Evo Morales, en particular porque privilegia la recuperación ante la oportunidad de iniciar un proceso de negociación que se caracterice efectivamente por una transacción. Esencial es también la institucionalización de la demanda marítima en Bolivia, que con el tiempo ha instaurado la reivindicación marítima como parte de la identidad boliviana, en forma más notoria en la Constitución de 2009, la conmemoración del Día del Mar cada 23 de marzo que se viste con un elocuente discurso presidencial, y en la burocracia administrativa que últimamente se ha construido en torno al tema, con la creación del Consejo de Reivindicación Marítima y la Dirección Estratégica de Reivindicación Marítima. El asunto es particularmente sensible ante la postura boliviana que es agresiva en su planteamiento constitucional, políticamente provocadora en el discurso interno y muy activa en el ámbito internacional, especialmente en la judicialización de la demanda con la presentación ante la Corte Internacional de Justicia en La Haya. No obstante lo anterior, se estima como posible un cambio de dirección en el mediano plazo, que en lo político, abra las puertas al diálogo. El trasfondo lo establece la reivindicación como concepto, que trasciende la "cualidad marítima", incluso sobrepasa al Tratado de 1904, donde la recuperación se impone como principio.

En cambio, es prácticamente imposible alterar las condicionantes estratégicas en Chile. Como consecuencia, parece extremadamente remota la posibilidad de entregar soberanía. Dividir el territorio en dos con un corredor al sur de Tarapacá, con soberanía boliviana desde el altiplano al Pacífico, solo aislaría al extremo norte de Chile. Por otra parte, un enclave boliviano tendría la tendencia de proyectar soberanía boliviana al territorio chileno y complicaría las relaciones en la serie de complejidades diarias de tránsito por territorio chileno. Una franja en el extremo norte del país tampoco se ve viable en atención a la historia de Perú y Bolivia y el testimonio que tenemos con el 
Tratado de 1929, en que Perú prefiere entregar territorio al adversario (Chile) antes que al otrora aliado (Bolivia).

\section{Referencias bibliográficas}

_Tratado de paz entre Chile y Perú. 28 de julio, 1929. Disponible el 29 de diciembre, 2014 en: http://www.memoriachilena.cl/602/w3-article-71928.html

CEEAG. "Relaciones Chile-Bolivia Implicancias para la Defensa". Ciclo de Conferencias ofrecidas por el Centro de Estudios Estratégicos de la Academia de Guerra del Ejército (CEEAG) al Ejército de Chile. Sep-Nov, 2014.

ESTADO PLURINACIONAL DE BOLIVIA. Constitución Política del Estado. La Paz: Gaceta Oficial de Bolivia. 2009.

ESTADO PLURINACIONAL DE BOLIVIA. Plan Nacional de Desarrollo. Lineamientos Estratégicos 2006-2011. Publicado como anexo al Decreto Supremo 29272, del 12 de septiembre de 2007. La Paz: Gaceta Oficial de Bolivia. 2007.

MARTíNEZ de Murguía, Beatriz. Mediación y resolución de conflictos. Ciudad de México: Paidós. 1999.

MINISTERIO DE RELACIONES EXTERIORES DE CHILE. Chile y la aspiración marítima boliviana. Mito y realidad. Publicación oficial. Junio, 2014. Disponible el 29 de diciembre, 2014

en:

http://www.minrel.gob.cl/minrel/site/artic/20140624/asocfile/20140624134912/chi le_y_la_aspiraci_n_mar_tima_boliviana_mito_y_realidad.pdf

VERGARA C. y TORO I. “Gobierno boliviano aclara que dichos de Morales sobre Atacama fueron "una broma”". La Tercera, 23 de enero. 2011. 